Chomitz, Thomas and Brandão Page 1

\title{
CREATING MARKETS For Habitat CONSERVATION WhEN HABITATS
}

\section{ARE Heterogeneous}

\author{
Kenneth M. Chomitz, Timothy S. Thomas, and Antônio Salazar Brandão
}

\section{Address for correspondence}

Kenneth M. Chomitz

World Bank

1818 H Street NW

Washington DC 20433

kchomitz@worldbank.org

\begin{abstract}
World Bank Policy Research Working Paper 3429, October 2004
The Policy Research Working Paper Series disseminates the findings of work in progress to encourage the exchange of ideas about development issues. An objective of the series is to get the findings out quickly, even if the presentations are less than fully polished. The papers carry the names of the authors and should be cited accordingly. The findings, interpretations, and conclusions expressed in this paper are entirely those of the authors. They do not necessarily represent the view of the World Bank, its Executive Directors, or the countries they represent. Policy Research Working Papers are available online at http://econ.worldbank.org.
\end{abstract}

Kenneth M. Chomitz is Senior Environmental Economist and Timothy S. Thomas is a consultant, with the World Bank, Development Research Group. Antônio Salazar Brandão is Professor of Economics, State University of Rio de Janeiro. We are grateful to IBGE for providing us with unpublished census-tract level tabulations of land cover, and to Fundação Getulio Vargas for providing the land value data. We have benefited greatly from discussions with and background material assembled by Ivana Lamas, Cláudia Costa, Luis Carlos Cardoso Vale, and José Roberto Soareas Scolforo. Aline Bernardes and Peter May provided useful comments and assistance. Preparation of this paper was supported by the Global Overlay Program, the Research Support Board, and by Norwegian assistance to the World Development Report 2003. 
Chomitz, Thomas and Brandão Page 2

\section{ABSTRACT}

A tradable development rights (TDR) program focusing on biodiversity conservation faces a crucial problem: defining which areas of habitat should be considered equivalent. Restricting the trading domain to a narrow area could boost the range of biodiversity conserved but could increase the opportunity cost of conservation.

The issue is relevant to Brazil, where TDR-like programs are emerging. Current regulations require each rural property to maintain a forest reserve of at least 20 percent, but nascent policies allow some tradability of this obligation. This paper uses a simple, spatially explicit model to simulate a hypothetical state-level program. We find that wider trading domains drastically reduce landholder costs of complying with this regulation and result in environmentally preferable landscapes.

Keywords: Brazil, conservation, environment, land use, Minas Gerais, tradable development rights JEL Classification: R52, Q24 
Chomitz, Thomas and Brandão Page 3

\section{INTRODUCTION}

Habitat conservation can be justified on instrumental or intrinsic grounds. The instrumental approach seeks ways to finance conservation of habitats that perform particular "bankable" services such as watershed protection or carbon storage (see e.g., Pagiola, Bishop and LandellMills 2002). If successful, this approach will create incentives to preserve some, but not all, habitats. It will promote conservation of moist hillside forests, for instance, and tend to neglect dry forests on plains — even if the latter contain unique biological features.

An alternative approach assumes a moral imperative to preserve viable examples of every type of natural habitat. Arguing from a well-established log-log relationship between habitat area and number of species, conservation biologists sometimes advocate a goal of retaining a fixed proportion - ten percent or more — of each habitat type. (Soulé and Sanjayan 1998) In many areas, this goal will not be met without active interventions to protect habitats from agricultural expansion. The costs of these interventions will vary widely, depending on agricultural potential and opportunities. In the developing world, the opportunity cost of conservation may be a few hundred dollars per hectare where the alternative is extensive pasture management, or thousands of dollars where the alternative is a high-value perennial crop.

In principle, a transferable development rights (TDRs) program can minimize the social cost of achieving a target for area conserved, and can reward those undertaking conservation. Such programs have been used on a small scale in the United States to preserve farmland and natural 
Chomitz, Thomas and Brandão Page 4 areas. (Johnston and Madison 1997) On a larger scale, a government could allocate development or conversion rights (denominated in hectares) equivalent to 80 percent of a particular habitat. Trading of these rights would tend to allow conversion of the plots most suitable for agriculture, and retention under natural vegetation of the areas with the lowest opportunity cost. If the rights were freely and equally allocated among property holders (a fiscally inefficient but politically expedient procedure), those who maintained forests would profit from TDR sales. A TDR program is thus the conservation analog of environmental permit programs that regulate air pollution or fisheries access.

The implementers of a TDR program focusing specifically on biodiversity representation face a crucial practical problem: defining which areas of habitat should be considered equivalent and substitutable $^{1}$. Science can provide input to this policy question, but cannot decide it. Forests (or other habitats) can be classified according to a detailed taxonomic hierarchy. Environmental policymakers may differ in their views on how far down the hierarchy to go in determining equivalence. "Lumpers" will favor equivalence within high level classifications, allowing substitutability among all neotropical forests, for instance. "Splitters" of different degrees of rigor will favor restricting forest substitutability to finer classifications, for instance, particular types of neotropical forests (e.g., moist neotropical rainforests), forest subtypes based on unique assemblages of species and communities (e.g., the Atlantic Rainforest of Brazil), forests within particular watersheds, or at the limit, forests within a particular microwatershed of a few thousand hectares. Choice of the appropriate level involves a tradeoff between the efficiency gains offered by a broad classification, and the potentially greater representation of biodiversity 
Chomitz, Thomas and Brandão Page 5

offered by a fine classification. (Consideration of environmental goals other than biodiversity, such as maintenance of hydrological processes, would complicate the tradeoff.)

This issue is of particular relevance to Brazil, where TDR-like programs are emerging. A longstanding regulation ${ }^{2}$ in Brazil requires each landowner to maintain a proportion of each property under natural vegetation as a legal forest reserve. The proportion ranges from 20 percent in southern Brazil to 80 percent in the Legal Amazon ${ }^{3}$. Recent provisional regulations allow landholders to satisfy the requirement for one property through legal forest reserve located on another. In some cases, the off-site legal reserve may be owned by another party, opening the way to a market in legal reserve rights.

This paper uses a simulation model to examine the impacts of alternative trading domains on landholder compliance cost and on protection of areas of biodiversity interest. It uses data for the Brazilian state of Minas Gerais, an innovator in the use of economic instruments for conservation. It significantly extends an earlier paper (Chomitz 2004) through improved measures of land value, finer geographic resolution, and a wider range of impact measures. While we believe that the results are indicative, we stress that this paper is not intended as an authoritative analysis for Minas Gerais. However, we hope that with further refinements, the model presented here could allow policymakers and stakeholders in Minas Gerais, in Brazil, and beyond to explore options and issues in policy design.

The next section describes the current situation in Minas Gerais. The third presents a stylized model illustrating the potential economic and environmental impacts of instituting alternative 
Chomitz, Thomas and Brandão Page 6 TDR schemes. The fourth section operationalizes the model. Section five presents our results with some discussion, and we end with some final comments.

\section{BRAZILIAN AND MINAS GERAIS CONTEXT}

Since 1965, Brazilian landholders have been obliged to keep a specified proportion of each property under natural vegetation. Currently, this "legal forest reserve" requirement is 20 percent in southern states - where much forest cover has been lost - and 80 percent in the forest-biome (e.g., non-savanna) areas of the Legal Amazon. Proprietors may use the legal reserve area for limited purposes, including sustainable extraction, but may not clear-cut it. The legal reserve requirement is additional to another regulation that places under "permanent protection" forested areas on hills or bordering streams and rivers.

Enforcing compliance with the legal reserve regulation is challenging in some southern states, where aggregate forest cover has been lost as a result of centuries of agricultural expansion, with much deforestation occurring in recent decades. In many locales, aggregate forest cover has dropped well below the 20 percent limit because of profitable opportunities to cultivate soybeans, vegetables, coffee, or other crops. Strict enforcement of the legal reserve requirement would be extremely expensive in these locales if landholders were required to abandon cropland or perennials. In heavily-worked properties with little remaining natural vegetation, the rate and quality of natural regeneration might be extremely slow. The isolated and poor-quality stands of regenerated vegetation would provide little biodiversity benefit. In other locales, some forest fragments persist. Often, these fragments represent the last vestiges of the Brazilian Atlantic 
Chomitz, Thomas and Brandão Page 7 Forest, a biome that is now reduced to about 7 percent of its original area and consequently harbors important biodiversity found nowhere else (Myers et al 2000). In Minas Gerais, the Atlantic Forest in 1995 had shrunk to 4.2 percent of its original area (Fundação SOS Mata Atlântica 1998). These fragments represent the candidates for nuclei of a regenerated forest, because of the potential to serve as genetic sources for endangered plants and animals. Yet deforestation continues in these forest fragments (Fundação SOS Mata Atlântica 1998) because returns to agricultural conversion and timber extraction exceed the private benefits of forest maintenance. The legal reserve regulation, by itself, would permit deforestation down to the 20 percent limit, though special regulations restrict deforestation in the Atlantic Forest zone.

In short, strict property-by-property enforcement of the legal reserve limit might be ecologically and economically inefficient in already-deforested regions. Property-wise enforcement would impose large compliance costs on profitable farms, with little environmental gain. Property-wise enforcement would fail to provide incentives to maintain and expand the precious remaining areas of primary habitat.

Consequently, as enforcement effort was stepped up in the late 1990s, there was increased attention to mechanisms that would allow out-of-compliance landholders to meet their legal reserve limits offsite. In the municipality of Araguarí, in the state of Minas Gerais, local prosecutors in 1997 allowed groups of coffee farmers, with no remaining forest on their properties, to form a "condominium" to purchase and preserve a large forested property (Bernardes 1999). In 1998, a federal-level provisional regulation permitted similar 
Chomitz, Thomas and Brandão Page 8 “compensation" procedures. The regulation has been repeatedly renewed, and contains a provision that specifies that compensation take place within the same microbasin if possible; and if not, in the same river basin and state $^{4}$. In 2002, Minas Gerais adopted a new state forest code, which allows for trading of legal reserve within a microbasin, but allows for some forms of legal reserve offset within a river basin. A more elaborate system of legal reserve enforcement and trading, SISLEG, was put in place in 2000 in the state of Paraná. (Keare and Barrows 2002) Each property in the state is required to come into compliance with the legal reserve requirement by the end of 2018. This can be done through on-site regeneration, with forested property of the same owner, or with forested property of a different owner. Cross-property compensation must take place within one of ten zones defined on the basis of river basins.

Forest reserve maintenance is particularly relevant to Minas Gerais. After suffering substantial forest loss, the Brazilian state of Minas Gerais has become an innovator in forest conservation. Over the past 50 years, forests in this large territory have been cleared to accommodate agricultural expansion and to fuel the state's charcoal-fired iron mills. Forest loss has been particularly severe in the Atlantic Forest region of the state, in the areas near the blast furnaces, and in the fertile "Triangulo" region in the west. In response, during the 1990s the state adopted two major conservation initiatives: a ban on the use of native forests for iron production, and a revenue-sharing system that rewarded municípios (the equivalent of counties) for creating and maintaining protected areas. Nonetheless, parks and reserves constitute only 0.9 percent of the state's territory; another 2.3 percent of the territory is in multiple use with some degree of 
Chomitz, Thomas and Brandão Page 9 environmental zoning (Costa et al 1998). Management of legal forest reserves on private lands is therefore of great significance to the state's overall forest estate.

Figure 1 shows remaining forest cover on private agricultural lands, based on municipio-level tabulations from the agricultural census of 1995/96 (IBGE 1998). The state is divided into four biomes, the major ones being the Atlantic Forest to the east, the cerrado or savanna to the west, and the caatinga in the drier north (Figure 2). Remaining forest cover is below 20 percent in most of the Atlantic Forest biome and in the agroclimatically favorable portions of the cerrado, to the south and west. Higher forest cover remains in the more arid and remote regions of the cerrado and caatinga. Average land values (Figure 3) are, not surprisingly, inversely related to forest cover $^{5}$.

\section{A SIMPLE MODEL OF THE APPLICATION OF A TDR SCHEME TO FOREST REGENERATION}

In areas with inadequate forest cover, the TDR scheme is a device to encourage protection of existing forest and regeneration of new forest. To evaluate its efficiency and effectiveness in doing so, we introduce a highly stylized model. Initially, a landholder has a property with total area $T$, of which $A_{0}$ is in agriculture and $F_{0}$ in forest. Then, a regulation is introduced (or enforced) requiring the landholder to set aside a proportion $\varphi$ of her property as forest reserve, 
Chomitz, Thomas and Brandão Page 10

first from existing forest, and then if necessary by abandoning cultivated land and pasture to forest regrowth. Let $g(x)$ represent the total value of the most valuable $\mathrm{x}$ hectares of cultivated land, and $h(x)$ the total value of the most valuable $\mathrm{x}$ hectares of forest land. We make the drastic assumption that forest reserve has no private value due to restrictions on use ${ }^{6}$. Then compliance with the regulation costs the landholder:

$$
\begin{gathered}
h\left(F_{0}\right)-h\left(F_{0^{-}} \varphi T\right) \quad\left(F_{0}>\varphi T\right) \\
h\left(F_{0}\right)+\left[g\left(A_{0}\right)-g\left(A_{0^{-}}\left(\varphi T-F_{0}\right)\right)\right] \quad\left(\varphi T>F_{0}\right)
\end{gathered}
$$

Regrowth occurs entirely on properties with low initial forest cover. Because these properties are likely to be the most productive and heavily worked, compliance costs are high, and the quality of regenerated forest likely to be low, due to compacted soil, nutrient depletion, and absence of seed sources ${ }^{7}$.

Now suppose that landholders are allowed to sell forest reserve rights attached to 'excess' forest (that is, forest areas in excess of $\varphi T$ ) and that those with forest reserve deficits may purchase these rights and apply them to their own reserve obligations. This creates a market for forest reserve with market-clearing price $\mathrm{p}$. The landholder's problem is to satisfy the legal reserve requirement by choosing an agricultural abandonment area $0 \leq a \leq A_{0}$, an on-site forest set-aside area $0 \leq f \leq F_{0}$ and a net legal reserve purchase area $\mathrm{q}(\mathrm{q}<0$ implies a sale of legal reserve rights) to maximize:

$$
g\left(A_{0^{-}} a\right)+h\left(F_{0-f}\right)-p q
$$


subject to :

$$
a+f+q \geq \varphi T
$$

The maximization problem will differ between forest-deficit and forest surplus properties, depending on some additional assumptions about allowable transactions.

Forest-deficit properties. First consider the response of properties where $F_{0}-\varphi T<0$. Suppose for simplicity (and reflecting likely legislation) that forest-deficit properties are required to place all existing forest under reserve $\left(f=F_{0}\right)$, and are not permitted to sell permits through forest generated by land abandonment. Their optimization problem is:

$$
\text { choose } a \text { to max } g\left(A_{0^{-}} a\right)-p \cdot\left(\varphi T-a-F_{0}\right)
$$

where the second term reflects the cost of purchasing permits, and the amount of permits is determined by the choice of $a$. When $p<g^{\prime}\left(A_{0}\right)$, compliance is achieved entirely through purchase of permits. When $p>g^{\prime}\left(A_{0^{-}}\left(\varphi T-F_{0}\right)\right)$, compliance is achieved entirely through abandonment of land. For intermediate values of $\mathrm{p}$ there is both abandonment and purchase, with $g^{\prime}\left(A_{0^{-}} a\right)=p$.

Forest surplus properties. If forest surplus properties are not permitted to sell permits based on agricultural land abandonment, then they choose f to maximize:

$$
h\left(F_{0-f)}+p \cdot(f-\varphi T)\right.
$$


Chomitz, Thomas and Brandão Page 12 where the second term reflects the potential revenue from sale of 'excess' reserve. Forest-surplus properties will convert all of their excess forest to farmland if $p<h^{\prime}\left(F_{0}-\varphi T\right)$. They will sell all their surplus equal to $F_{0}-\varphi T$ if $p>h^{\prime}(0)$. For intermediate values of $\mathrm{p}$, they sell $F_{0}>f>\varphi T$ satisfying $p=h^{\prime}\left(F_{0}-f\right)$. Whether sale of forest reserve rights constitutes an environmental gain depends on one's evaluation of the likelihood that this land would otherwise have eventually been converted or degraded in the future, and how irreversible that action would be. Positive land values for forests suggest that the option of future conversion is privately valuable, so that retirement of this option may be socially valuable if environmental benefits are taken into account.

If properties are allowed to sell permits based on agricultural land abandonment, then they choose both $\mathrm{f}$ and a to maximize

$$
g\left(A_{0^{-}} a\right)+h\left(F_{0-} f\right)-p(\varphi T-a+f)
$$

where there will be interior or corner solutions similar to those of the previous two cases. Here there could be an environmental gain if regeneration on these plots is vigorous and biodiverse due to the proximity of seed sources.

This simple model suggests that the environmental and economic impacts of a TDR scheme depend on whether land values and land cover vary substantially within areas deemed biologically homogeneous. Suppose, for instance, that agroclimatic conditions determine both land value and biodiversity. Areas favorable to agriculture will have distinct biota, but will tend 
Chomitz, Thomas and Brandão Page 13 to have low remaining forest cover and high land value. Demand for reserve rights will be high, but few properties will have surplus forest with which to supply that demand. Suppose on the other hand that land values are determined mainly by road access, and that there is substantial variation in road access within biologically homogeneous areas. In this case there are substantial gains from trade possible.

Environmental impacts also depend greatly on how the new scheme treats existing forest. If conversion of existing forest is allowed, especially in forest-deficit areas, then the TDR scheme could lead to loss of rare old-growth forests and its substitution by lower-quality regenerated forest. 
Chomitz, Thomas and Brandão Page 14

\section{IV.SIMULATION MODEL}

\section{$\underline{\text { Data }}$}

Land value. Land value data were kindly provided by Fundação Getulio Vargas. These data, collected semiannually, represent typical land sales transactions values by municipio for rural land sales, classified by land cover: crops, pasture, fields (campo) and forest. We chose second semester 1996 as the base period. Where observations were missing for this period, values were imputed using data from other periods, adjusted by average interperiod price change. Where data were missing for all periods, values were imputed from the average of neighboring municipios.

Land cover. The Censo Agropecuário 1995-96 (IBGE 1998) breaks down land use within agricultural establishments into the following categories: natural forest, planted forest, perennials, annuals, planted pasture, native pasture, short fallow, productive unutilized (probably long fallow), and nonproductive (e.g., rocks, water, paved areas). IBGE kindly provided us with these data at the level of the census tract; there are 8,123 census tracts in 756 municípios. To link land use data with land value data, we adopted the following rough concordance:

\begin{tabular}{|l|l|}
\hline Censo Agropecuario classification & FGV classification \\
\hline natural forest & forest (matas) \\
\hline perennials, annuals, planted forest & crops (lavouras) \\
\hline $\begin{array}{l}\text { planted pasture, short fallow, productive } \\
\text { non-utilized }\end{array}$ & pasture \\
\hline natural pasture & campo \\
\hline
\end{tabular}


Chomitz, Thomas and Brandão Page 15

Biodiversity priority areas. Biodiversity priority areas for the state were identified through a process described in Costa et al (1998). A 15-month process involving 121 experts identified conservation priority areas on the basis of species richness, species endemicity and distribution, threat, and presence of special biological characteristics. Priority maps were made for seven taxonomic groups and combined into a summary map (at a scale of 1:1,700,000) indicating four degrees of importance.

\section{Demand and Supply at the Micro Level}

Here we adapt the theoretical model of section 3 to the available data. The unit of observation is the census tract. Census tract $i$ in municipio $j$ has $T_{i j}$ total hectares in agricultural establishments (excluding unproductive land), of which $F_{i j}$ is in forest, $A_{i j}$ in crops, $C_{i j}$ in native pasture, and $D_{i j}$ in planted pasture. We assume that, within each of these land uses, land is of homogeneous quality within município $j$ and has value per hectare $V_{k j}$, where $k$ indexes land use. We assume that properties within the census tract can pool their forest holdings for the purpose of satisfying the legal reserve requirement. If $f_{i j}=F_{i j} / T_{i j}<0.2$, then the unit is out of compliance by a gap G $=0.2 \mathrm{~T}_{\mathrm{i}}-\mathrm{F}_{\mathrm{i}}$. Within the census tract, it can come into compliance either by purchasing legal reserve rights or by abandoning productive land to forest regrowth. ${ }^{8}$ It chooses the least costly strategy, abandoning successively higher cost land until the opportunity cost of abandonment is the same as the price of legal reserve. We will assume that out-of-compliance properties are not permitted to use natural regeneration to create "excess" legal reserve for sale.

Let $q_{i j}(p)$ be the cumulative nonforest area in tract $i j$ with value per hectare less than $p$. This distribution is approximated by constructing a step function based on $A_{i j}, C_{i j}$, and $D_{i j}$ together 
Chomitz, Thomas and Brandão Page 16 with their corresponding average values $V_{a j}, V_{c j}, V_{d j}$. For instance, where $V_{c j}<V_{d j}<V_{a j}$, the inverse of $q($.$) is given by:$

$$
\begin{array}{ll}
p=V_{c j} & {\left[0<q<C_{i j}\right]} \\
p=V_{d j} & {\left[C_{i j}<q<C_{i j}+D_{i j}\right]} \\
p=V_{a j} & {\left[C_{i j}+D_{i j}<q<C_{i j}+D_{i j}+A_{i j}\right]}
\end{array}
$$

This crude approximation assumes that heterogeneity in land quality among farms within a município is reflected in different allocations of land use rather than in different average valuations of land devoted to particular land uses.

The tract's demand for legal reserve at price $p$ is $d_{i j}(p)=\max \left[0, G-q_{i j}(p)\right]$. When $f_{i j}>0.2$, the census tract is a potential supplier of legal reserve. The supply function is $\operatorname{simply} s_{i j}(p)=0$, if $p$ $<V_{f j}$, and equals $F_{i j}-0.2 T$, if $p>V_{f j}$.

In areas where the aggregate proportion of native forest falls below 20 percent, long-term ecosystem viability may depend on expanding the size of forest patches through natural regeneration of adjacent areas. It may therefore be desirable to allow properties (census tracts) that already have substantial forest cover to supply additional forest reserve through abandonment and regeneration. Supposing that this option is limited to census tracts with $f_{i j}>$ 0.2 , the additional supply is given by $s_{i j}^{a d d}(p)=q_{i j}(p)$. 
Chomitz, Thomas and Brandão Page 17

\section{$\underline{\text { Solving for Market Equilibrium and its Impacts }}$}

Aggregation of $s_{i j}(p)$ and $d_{i j}(p)$ over any specified trading domain yields estimates of the aggregate supply and demand curves $S(p)$ and $D(p)$. The calculated supply and demand functions are biased approximations of the actual functions. The crude imputation of land values used here does not take account of heterogeneity of land quality. Nor does it allow for the likely relationship between land cover and land value. Areas with relatively high forest cover are likely to be areas where agricultural potential, and hence land values, are low. (It is for this reason that the forest is still standing.) Hence the derived supply and demand functions are likely to differ systematically from the true functions, with less supply at low prices and less demand at high prices. This bias should be kept in mind when assessing model results.

Equating supply and demand yields an equilibrium price $p^{*}$ and quantity $Q^{*}$. Substitution of equilibrium price into a census tract's supply and demand functions allows computation of legal reserve bought and sold, expenditures and revenues related to these transactions, of forest area newly-protected as legal reserve, and of areas abandoned to regeneration.

Economic and environmental effects are assessed relative to an assumed 'command-and-control' baseline scenario. In the baseline case, the legal reserve requirement is enforced on a propertywise basis without trading. In the baseline, we assume that areas with more than 20 percent forest eventually reduce forest cover to the legal limit (except in the Atlantic Forest biome where deforestation is forbidden), ${ }^{9}$ and that areas that are out of compliance use unassisted natural regrowth on abandoned land to come into compliance. 
Chomitz, Thomas and Brandão Page 18

The reduction in compliance cost (relative to property-wise enforcement of the legal reserve requirement) is given by:

$$
\int_{Q=0}^{Q^{*}} D^{-1}(Q) d Q-p^{*}
$$

Rents earned by the suppliers of legal reserve are given by:

$$
p^{*}-\int_{Q=0}^{Q^{*}} S^{-1}(Q) d Q
$$

The hypothetical TDR program potentially benefits the environment by encouraging the conservation and expansion of forest fragments in forest-rich locales. In the baseline scenario, these ecologically valuable areas are allowed to degrade down to the 20 percent limit, while areas that are already severely degraded are allowed to present very poor-quality regeneration to fulfill their reserve requirement. (The regeneration in these areas is likely to be poor because seed sources are lacking and the land has been heavily worked). In the program scenario, standing forest is conserved, and regrowth is encouraged near the forest, where seed sources are plentiful, and the opportunity to reconnect forest fragments is greater. This should lead to higher biomass and carbon densities, and to ecosystems better to support minimum viable populations of flora and fauna. 
Chomitz, Thomas and Brandão Page 19

To compute biodiversity impacts, municipio-level impacts were proportionately allocated to biodiversity priority areas that overlapped with the municipio. (Unfortunately the census-tract level data were not spatially referenced.)

\section{RESULTS}

Table 1 compares the impacts of alternative enforcement scenarios, relative to a baseline of no enforcement of the forest reserve regulation. In the command and control scenario, no trading of forest reserve permits is allowed. Successive scenarios allow trading within expanding geographic domains: municipio, biome $\mathrm{X}$ river basin combination, biome. Within each of the geographic trading regimes, two sub-scenarios are simulated. In 'forest only', forest surplus properties may sell permits based only on existing 'excess' forest. In the 'forest first' scenarios, forest surplus properties may also sell permits from abandonment and regrowth on agricultural plots, but only after selling all available permits based on standing forest.

In the command and control scenario, out-of-compliance landholders come into compliance by abandoning 3,146,000 hectares of farmland, at an opportunity cost of $\mathrm{R} \$ 1.47$ billion. All of this is assumed to become low quality regeneration. The municipio-level trading scenarios offer negligible reductions in total compliance cost, as within-municipio trading opportunities are few. (This reflects to some degree the assumption of homogeneous land prices, for a given land use type, within municipios, but also the observed infrequency of coexisting forest-deficit and forest- 
Chomitz, Thomas and Brandão Page 20 surplus census tracts within the same municipio.) For the biome-basin scenario, however, trading makes a difference. In the forest-only sub-scenario, total compliance costs decline by $\mathrm{R} \$ 256$ million relative to the command and control scenario. Forest-deficit properties capture about 45 percent of this saving. The rest goes to forest-surplus properties, which sell permits based on 346,000 forest hectares placed under new protection, and 250,000 hectares already protected (in theory) by regulations forbidding Atlantic Forest deforestation. In the forest-first subscenario of biome-basin trading, there is a further reduction of $\mathrm{R} \$ 220$ million in the social costs of compliance. The bulk of this accrues to the forest-deficit landholders, who now abandon only 1,745,000 hectares, purchasing permits from 977,000 hectares of regenerating forest in favorable areas. Compared to the forest-only subscenario, new protection of existing forest drops from 346,000 to 175,000 hectares.

In the final pair of scenarios, trading is permitted throughout a biome. The forest-only variant shows relatively little difference in the land cover mix from biome-basin trading: newly protected forest increases in area from 346,000 to 455,000 hectares. But by exploiting crossbasin (but within-biome) differences in land value, the biome-wide trading scenario reduces costs by an additional $\mathrm{R} \$ 284$ million compared to biome-basin. Finally, compliance costs are drastically reduced in the final scenario, the forest-first variant of biome-wide trading. Compared to the command-and-control scenario, total opportunity costs are reduced by over R $\$ 1$ billion, most of which accrues to forest-deficit landholders. The savings accompanies a massive shift of 1.7 million hectares from land under low-quality regeneration to land under high-quality regeneration. Compared to the forest-only variant of biome-wide trading, this environmental 
Chomitz, Thomas and Brandão Page 21 benefit is slightly offset by a decline in new protection of standing forest, from 455,000 hectares to 275,000 hectares. Forest -surplus landholders realize reduced aggregate profits from permit sales in the forest-first variant, despite the much greater hectarage of permits delivered.

Figure 4 summarizes the main results, showing only the forest-first variants. Expansion of the trading domain results in substantial social savings; both forest-deficit and forest-surplus landholders benefit as the domain expands. Wider trading also results in a better overall quality of new additions to the forest reserve system. Under command-and-control, the new reserves are entirely composed of low-quality regeneration. Much of this area will regenerate weakly, if at all, yielding little biodiversity or carbon sequestration benefit. Under biome-wide trading, lowquality regeneration is reduced to just 29 percent of the expanded reserve area. This almost certainly implies some gain in carbon sequestration and improvement in biodiversity-friendly habitat. But does expansion of the trading domain lead to poor targeting or poor geographical balance in the biodiversity benefits?

While enforcement of command-and-control protects an additional 486,000 hectares of poorquality regenerating land in biodiversity priority areas, biome-basin trading protects 668,000 new hectares in these areas (of which 427,000 is standing forest or high quality regeneration) and biome-wide trading protects 884,000 new hectares in biodiversity priority areas, mostly highquality. Figures 5 and 6 show how the geographic distribution of high quality forest (i.e., existing, and high quality regeneration) differs between biome-basin trading, and biome-wide trading. Biome-wide trading has large beneficial impacts on forest extent in the north and east of 
Chomitz, Thomas and Brandão Page 22 the state, both inside and outside biodiversity priority areas. Biome-basin trading yields superior results only in some small corners of the southwestern portion of the state. In this fertile agricultural area, permit prices soar to over $\mathrm{R} \$ 1,100$ per hectare when trading is restricted to the biome-basin combination, eliciting some supply from the few remaining forest-surplus tracts.

\section{VI.DISCUSSION AND CONCLUSIONS}

The simulation results show that a tradable development rights program could dramatically reduce the opportunity costs of protecting and regenerating a desired aggregate level of forest cover, when the trading domain extends beyond the strictly local area (e.g. municipio or microwatershed). Trading beyond the local level also results in superior environmental results, including greater protection of existing forest remnants, and encouragement of higher-quality regeneration. These outcomes should be better both for biodiversity and for carbon sequestration. These results may be generalizable to other forest-poor areas, since they follow from the strong association between favorable agroclimatic and market access conditions, high prior levels of forest conversion, and high land values, and high degrees of spatial autocorrelation in all these variables.

Reduction in opportunity costs is important not just from the viewpoint of economic efficiency, but perhaps more importantly, from a political economy viewpoint. Much of the cost reductions would potentially accrue to large landholders in rich agricultural regions. But benefits also accrue to landholders in less prosperous regions who have protected their forests, and to agricultural workers. Together this builds a powerful constituency for instituting the program. 
Chomitz, Thomas and Brandão Page 23

Conversely, there would be little support for a command-and-control program that imposed costs on these stakeholder groups.

How far should trading domains be extended? There cannot be a definitive answer, as the tradeoffs will be sensitive to the spatial covariance of biological distinctiveness and agricultural attractiveness - and to decisions about how to share the costs of conservation. But the results shown here suggest that wider domains deserve serious attention - at least in the context where forests are already depleted in high-market-value areas. Here the wider domain offers much greater aggregate environmental benefits and much greater social savings. The savings are large enough that a small portion could be used to finance targeted interventions (such as purchase of land for parks) in ecosystems that might otherwise be underrepresented. Similar considerations apply when considering whether to allow permit supply only from standing forest, or also from regeneration. Similarly, extending the trading regime to allow supply of permits from highquality regeneration 'crowds out' a small amount of protection of standing forest, but stimulates the creation of a much greater extent of restored forest, while realizing considerable savings. Again, in principle, some of the savings could be devoted to targeted acquisition of standing forest in underrepresented ecosystems.

A deeper understanding of the potential for instituting tradable development rights programs requires two lines of investigation. First, modeling can be improved through more accurate representation of economic and ecological conditions and processes. Finer spatial detail on land values, more realistic modeling of 'business as usual' land use trends, and ecologically-informed 
Chomitz, Thomas and Brandão Page 24 modeling of the vigor of natural regeneration would all help. Second, implementation of these programs requires more investigation into the institutional mechanics of monitoring and enforcement, and the political economy of adoption.

Perhaps the biggest question is whether such programs are feasible in places that lack Brazil's tradition of a quantitative conservation requirement for every landholder. Certainly the existence of that tradition makes it easier to reach consensus on an initial allocation of permits. But it may also be possible to agree on such a rule in areas where forests have been widely cut despite legal prohibitions; or in forest-rich regions where publicly owned lands are only now coming under development pressure. In any case, the evolution of TDR-like systems in Brazil alone is reason enough for serious policy and research attention to the issue. 
Chomitz, Thomas and Brandão Page 25

\section{REFERENCES}

Bernardes, Aline T. 1999. "Some Mechanisms for Biodiversity Protection in Brazil, with Emphasis on their Application in the State of Minas Gerais." Paper prepared for the Brazil Global Overlay Project, Development Research Group, World Bank.

Costa, Cláudia Maria Rocha, Gisela Herrmann, Cássio Soares Martins, Lívia Vanucci Lins, and Ivana Reis Lamas. 1998. Biodiversidade em Minas Gerais: Um Atlas Para sua Conservação. Belo Horizonte: Fundação Biodiversitas.

Chomitz, Kenneth M. 2004. "Transferable Development Rights and Forest Protection: An Exploratory Analysis." International Regional Science Review 27(3): 348-73.

IBGE 1998. Censo Agropecuario: Minas Gerais. Rio de Janeiro: IBGE.

Johnston, R., and M. Madison. 1997. "From Landmarks to Landscapes: A Review of Current Practices in the Transfer of Development Rights." Journal of the American Planning Association 63(3): 365-78.

Keare, Douglas, and Richard Barrows. 2002. "Survey of Economic Instruments for Land Management in Developing Countries." Prepared for the Development Research Group, World Bank. Processed.

Myers, Norman, Russell A. Mittermeier, Cristina G. Mittermeier, Gustavo A. B. da Fonseca, and Jennifer Kent. 2000. "Biodiversity Hotspots for Conservation Priorities." Nature 403:853-58.

National Research Council. 2001. Compensating for Wetland Losses under the Clean Water Act. Washington DC: National Academy Press.

Pagiola, Stefano, Joshua Bishop, and Natasha Landell-Mills. 2002. Selling Forest Environmental Services: Market-based Mechanisms for Conservation and Development. London: Earthscan.

Soulé, Michael E., and M. A. Sanjayan. 1998. "Conservation Targets: Do They Help?" Science 279: 2060-61

Whigham, Dennis F. 1998. "Ecological Issues Related to Wetland Preservation, Restoration, Creation, and Assessment." Science of the Total Environment 240: 31-40. 


\section{Chomitz, Thomas and Brandão Page 26}

\section{NOTES}

\footnotetext{
${ }^{1}$ It has similarly proved difficult to operationalize wetland equivalence for the application of compensatory schemes for wetland mitigation. There, the problem is commensurating a wide range of distinct hydrological and biological functions. See Whigham 1999 and National Research Council 2001.

${ }^{2}$ The regulation was incorporated in the Forest Code of 1965, and had a precursor in the 1934 Code.

${ }^{3}$ Landholders are additionally required to maintain vegetation in areas of permanent preservation, which include riverbanks and slopes.

${ }^{4}$ Medida Provisória 2166-67, 24 August 2001 is the most recent versión.

${ }^{5}$ This is true in part by construction. Mean land values are computed as the weighted average of prices according to land class, with forest often being the least valuable class.

${ }^{6}$ Think of the value of existing, non-reserved forest as representing the sum of option values for agricultural use and the value of standing timber if liquidated immediately. This value may be large relative to the present value of a stream of sustainable forest harvests, particularly from newly regenerating forest.

${ }^{7}$ This generalization may not apply to areas under perennial crops or plantations, some of which may revert easily to forest if abandoned.

${ }^{8} \mathrm{We}$ assume that such abandonment satisfies regulations, regardless of the actual quality of subsequent natural regeneration.

${ }^{9}$ Despite this law 7.3 percent of the remaining Atlantic Forest in Minas Gerais was deforested over 1990-95 according to a remote sensing-based study (SOS Mata Atlântica 1998)
} 
Chomitz, Thomas and Brandão Page 27

Table 1 Economic and environmental impacts of alternative scenarios

\begin{tabular}{|c|c|c|c|c|c|c|c|}
\hline & \multirow{2}{*}{$\begin{array}{r}\text { Command } \\
\& \text { control }\end{array}$} & \multicolumn{2}{|c|}{ Municipio } & \multicolumn{2}{|c|}{ Biome-basin } & \multicolumn{2}{|c|}{ Biome } \\
\hline & & $\begin{array}{r}\text { Forest } \\
\text { only }\end{array}$ & $\begin{array}{r}\text { Forest } \\
\text { first }\end{array}$ & $\begin{array}{r}\text { Forest } \\
\text { only }\end{array}$ & $\begin{array}{r}\text { Forest } \\
\text { first }\end{array}$ & $\begin{array}{r}\text { Forest } \\
\text { only }\end{array}$ & $\begin{array}{r}\text { Forest } \\
\text { first }\end{array}$ \\
\hline Number of trading domains & NA & \multicolumn{2}{|c|}{756} & \multicolumn{2}{|l|}{15} & \multicolumn{2}{|c|}{4} \\
\hline Forest accounting & \multicolumn{7}{|c|}{ (Thousands of hectares. Baseline is 4.837 million hectares.) } \\
\hline Abandoned in deficit forest areas & 3,146 & 3,024 & 2,861 & 2,551 & 1,745 & 2,441 & 904 \\
\hline $\begin{array}{l}\text { Leased in from surplus forest } \\
\text { areas, of which: }\end{array}$ & 0 & 122 & 285 & 596 & 1,401 & 706 & 2,243 \\
\hline $\begin{array}{l}\text { - in forest but not currently } \\
\text { protected }\end{array}$ & 0 & 51 & 40 & 346 & 175 & 455 & 275 \\
\hline est land abandoned & 0 & 0 & 174 & 0 & 977 & 0 & 1,717 \\
\hline - in forest and already protected & 0 & 71 & 71 & 250 & 250 & 251 & 251 \\
\hline Total existing forest protected & 4,837 & 4,888 & 4,877 & 5,183 & 5,012 & 5,292 & 5,112 \\
\hline $\begin{array}{l}\text { Forest and higher quality } \\
\text { regeneration }\end{array}$ & 4,837 & 4,888 & 5,051 & 5,183 & 5,989 & 5,292 & 6,829 \\
\hline all regeneration & 7,983 & 7,912 & 7,912 & 7,734 & 7,734 & 7,733 & 7,733 \\
\hline Biodiversity a & \multicolumn{7}{|c|}{ (Thousands of hectares. Baseline is 1.075 million hectares.) } \\
\hline $\begin{array}{l}\text { New, by abandonment in forest } \\
\text { deficit areas }\end{array}$ & 486 & 453 & 403 & 384 & 241 & 423 & 235 \\
\hline $\begin{array}{l}\text { New, by leasing out in forest } \\
\text { surplus areas }\end{array}$ & 0 & 33 & 82 & 182 & 427 & 215 & 649 \\
\hline Total & 1,561 & 1,561 & 1,561 & 1,642 & 1,743 & 1,713 & 1,959 \\
\hline Econo & \multicolumn{7}{|l|}{$(000 s \mathrm{R} \$)$} \\
\hline $\begin{array}{l}\text { Opportunity cost of abandoned } \\
\text { land in forest-deficit tracts }\end{array}$ & \multicolumn{6}{|c|}{$1,469,2521,426,4531,359,157$ 1,147,322 797,980 813,857 } & 131,146 \\
\hline Exper & 0 & 28,387 & 91,010 & \multicolumn{3}{|c|}{$206,439376,571469,274$} & 478,925 \\
\hline Profits from sales of permi & 0 & 15,242 & 26,568 & \multicolumn{3}{|c|}{$141,249182,067354,773$} & 206,107 \\
\hline $\begin{array}{l}\text { Reduction in compliance costs } \\
\text { for forest-deficit tracts }\end{array}$ & 0 & 14,413 & 19,094 & \multicolumn{3}{|c|}{$114,432293,642184,791$} & 859,760 \\
\hline Total surplus & 0 & 29,655 & 45,663 & \multirow{2}{*}{\multicolumn{4}{|c|}{$255,681475,709539,565$ 1,065,866 }} \\
\hline \multirow{2}{*}{\multicolumn{8}{|c|}{$\begin{array}{l}\text { Notes: } \\
\text { a) By law, property owners are required to leave } 20 \text { percent of their land in forest. Also, trees are not allowed to be cut in the Atlantic } \\
\text { Forest biome. The baseline forest is calculated as the lesser of existing forest and } 20 \text { percent of productive land; except in the } \\
\text { Atlantic Forest biome, where it is equal to the existing forest. } \\
\text { (b) "Abandoned" refers to any land that was not in forest that is allowed to regenerate naturally to forest. We assume "strong } \\
\text { regeneration" occurs in areas that have at least } 20 \text { percent of the potentially productive land currently in forest ("forest surplus } \\
\text { areas"). Areas with less than } 20 \text { percent of the land in forest are called "forest deficit areas". }\end{array}$}} \\
\hline & & & & & & & \\
\hline \multicolumn{8}{|c|}{$\begin{array}{l}\text { (c) Under the trading regimes, the supply price of forested land in the Atlantic Forest biome is set } \\
\text { to } 0 . \\
\text { (d) "In forest and already protected" represents forested land in the Atlantic Forest biome that is above the } 20 \text { percent required in } \\
\text { other biomes. We allow sales of permits based on this forest. }\end{array}$} \\
\hline
\end{tabular}


Chomitz, Thomas and Brandão Page 28

(e) Biodiversity area preserved is calculated by multiplying the area of abandonment (of deforested land) or protection of forested land, times the proportion of the municipio which is in a biodiversity priority area. The biodiversity area baseline is calculated from the baseline forest area.

f) "Lost value from abandoning land" is computed as the area under the demand curve: the value of land in forest deficit areas. 
Chomitz, Thomas and Brandão Page 29

Figure 1: Forest cover on private agricultural land, by municipio, 1996

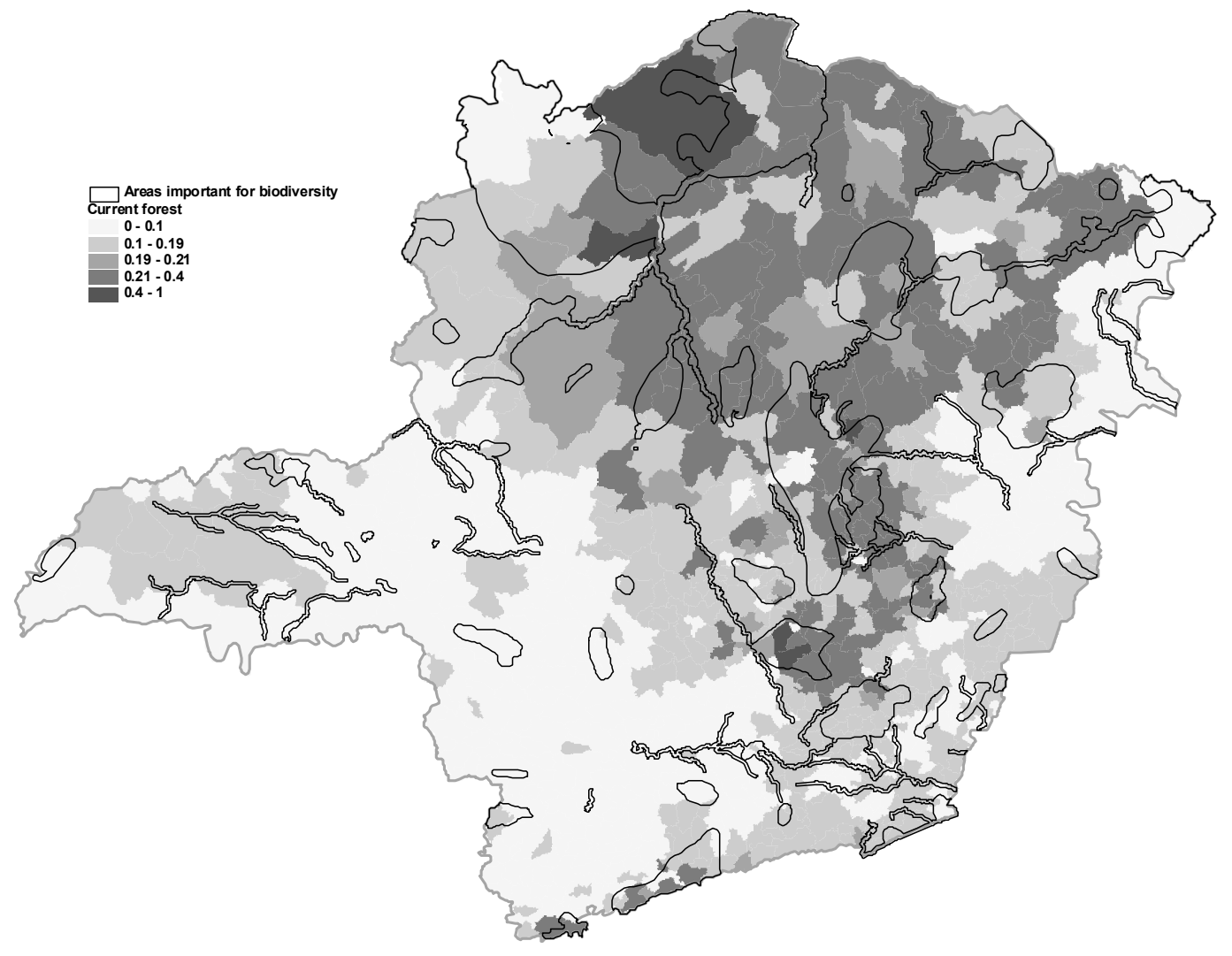


Figure 2. Biomes and major river basins

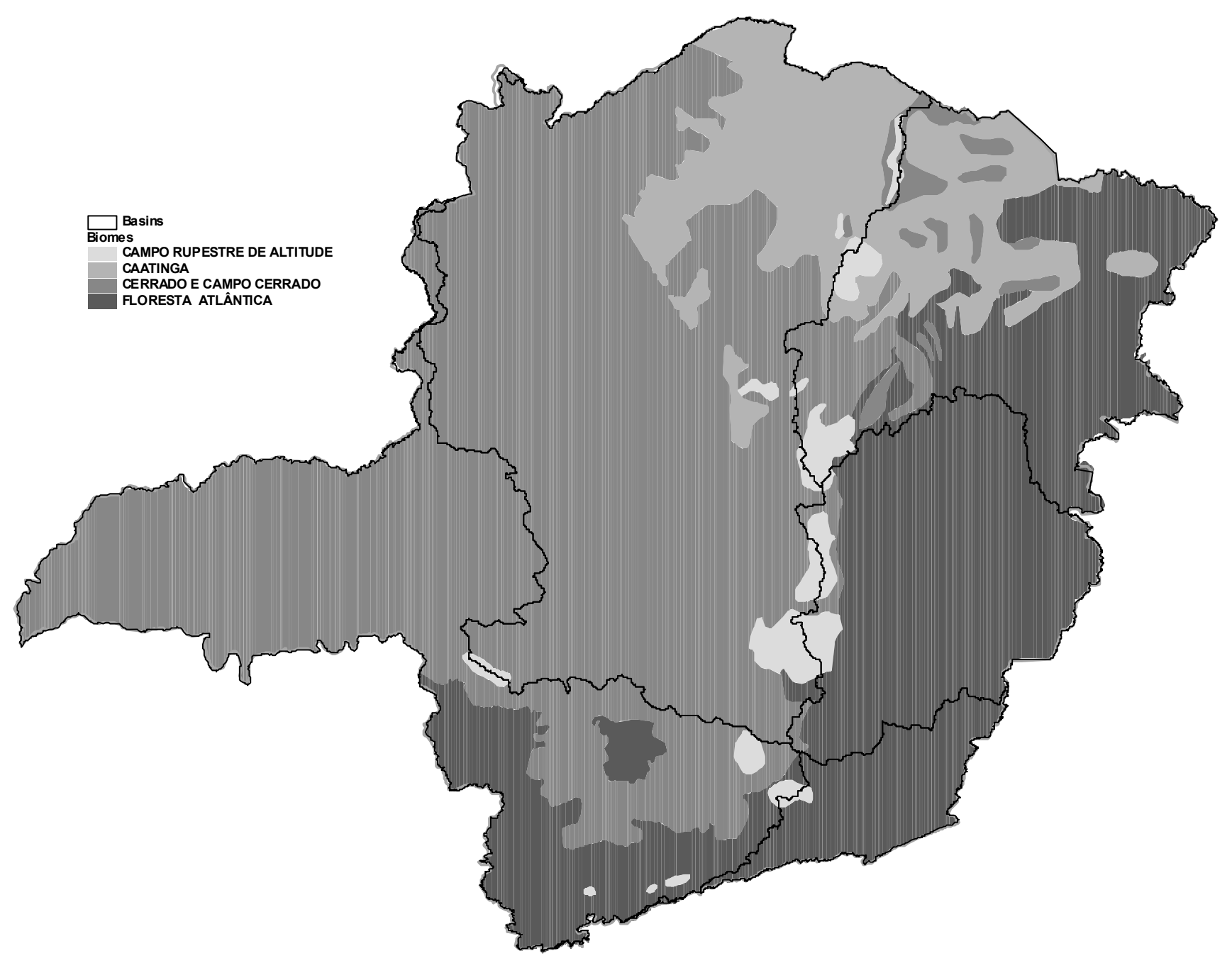


Chomitz, Thomas and Brandão Page 31

Figure 3 Land values

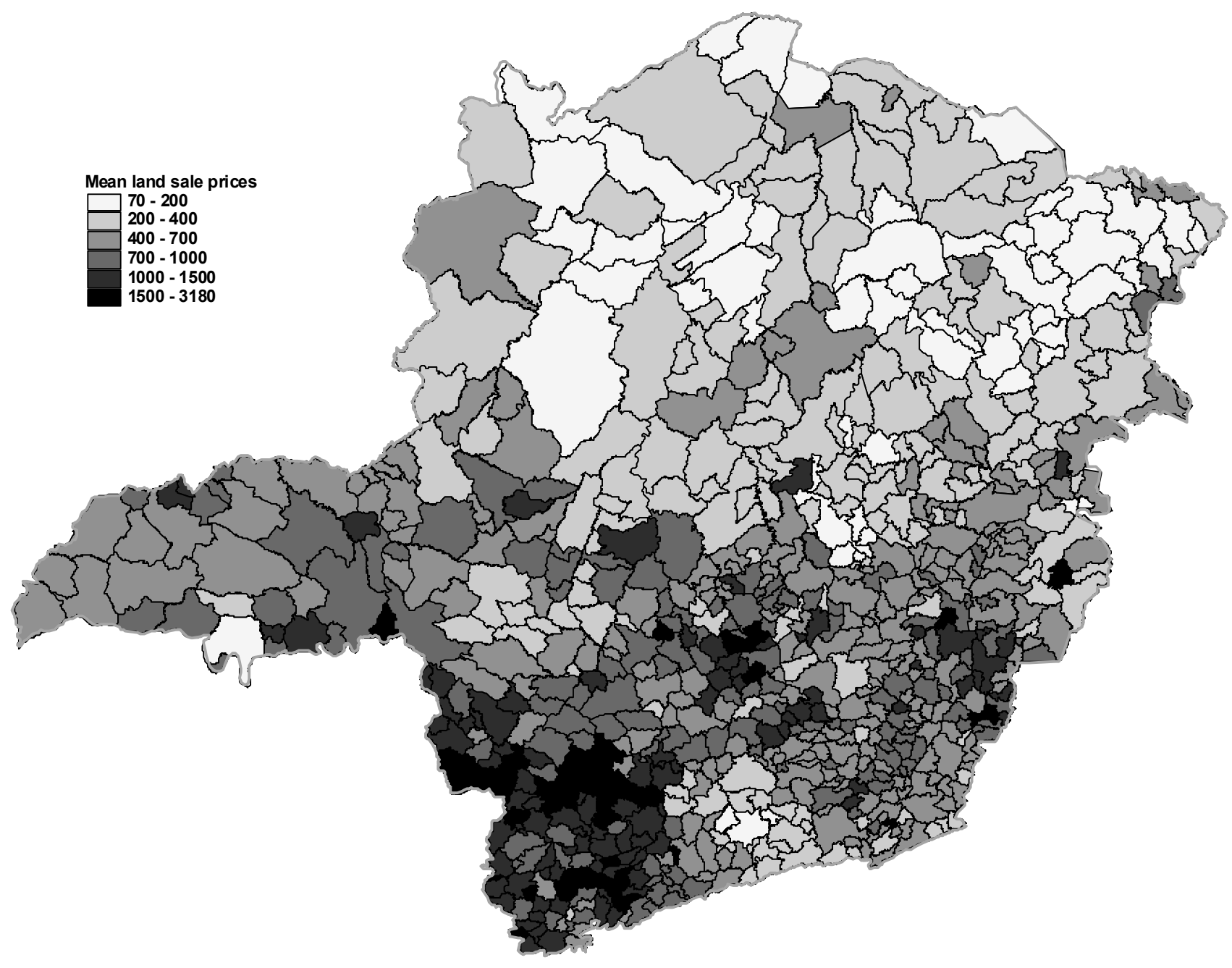


Chomitz, Thomas and Brandão Page 32

Figure 4 Summary of economic and environmental impacts of alternative trading domains

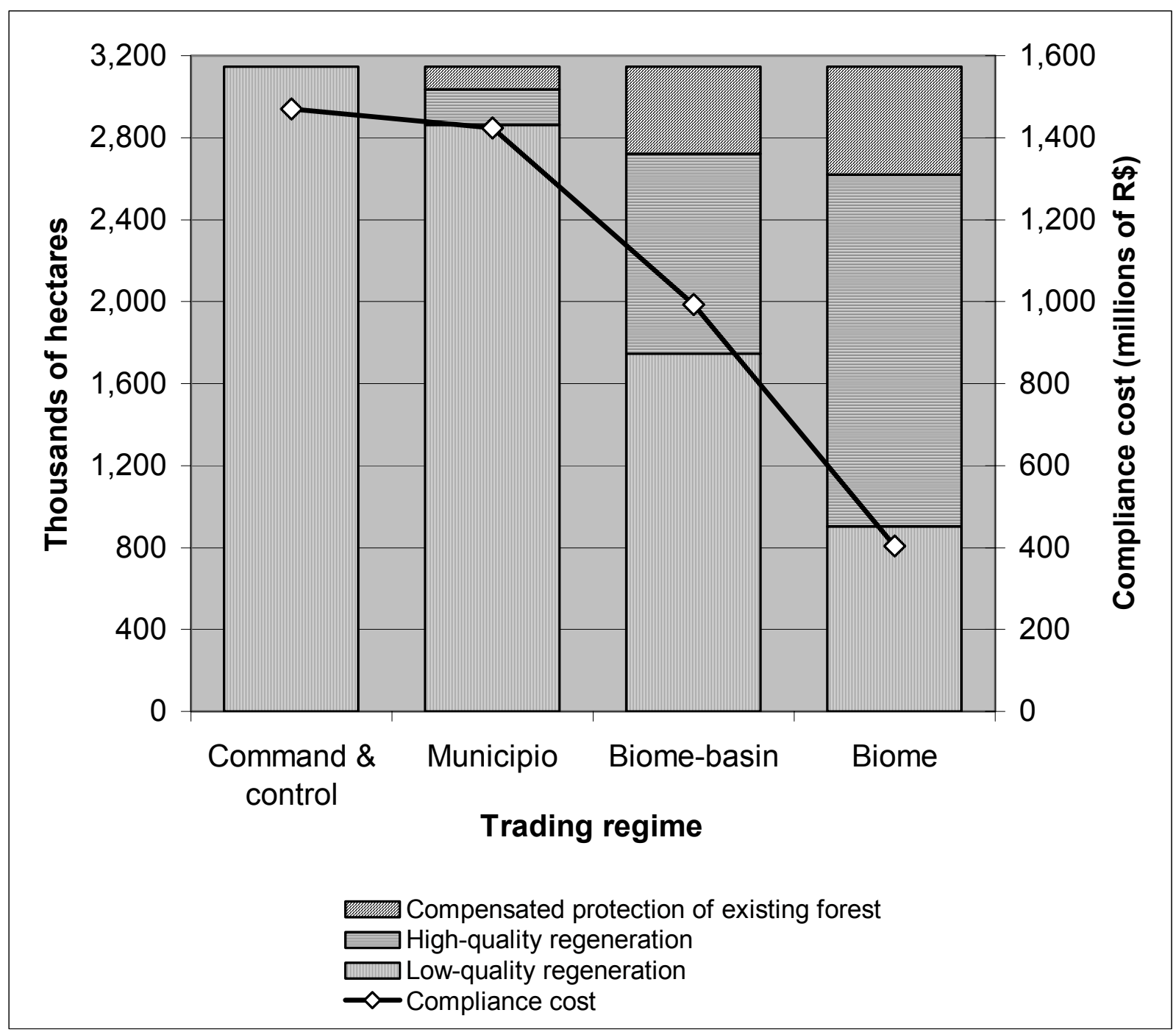


Chomitz, Thomas and Brandão Page 33

Figure 5 "Good-quality" forest cover with biome-basin trading

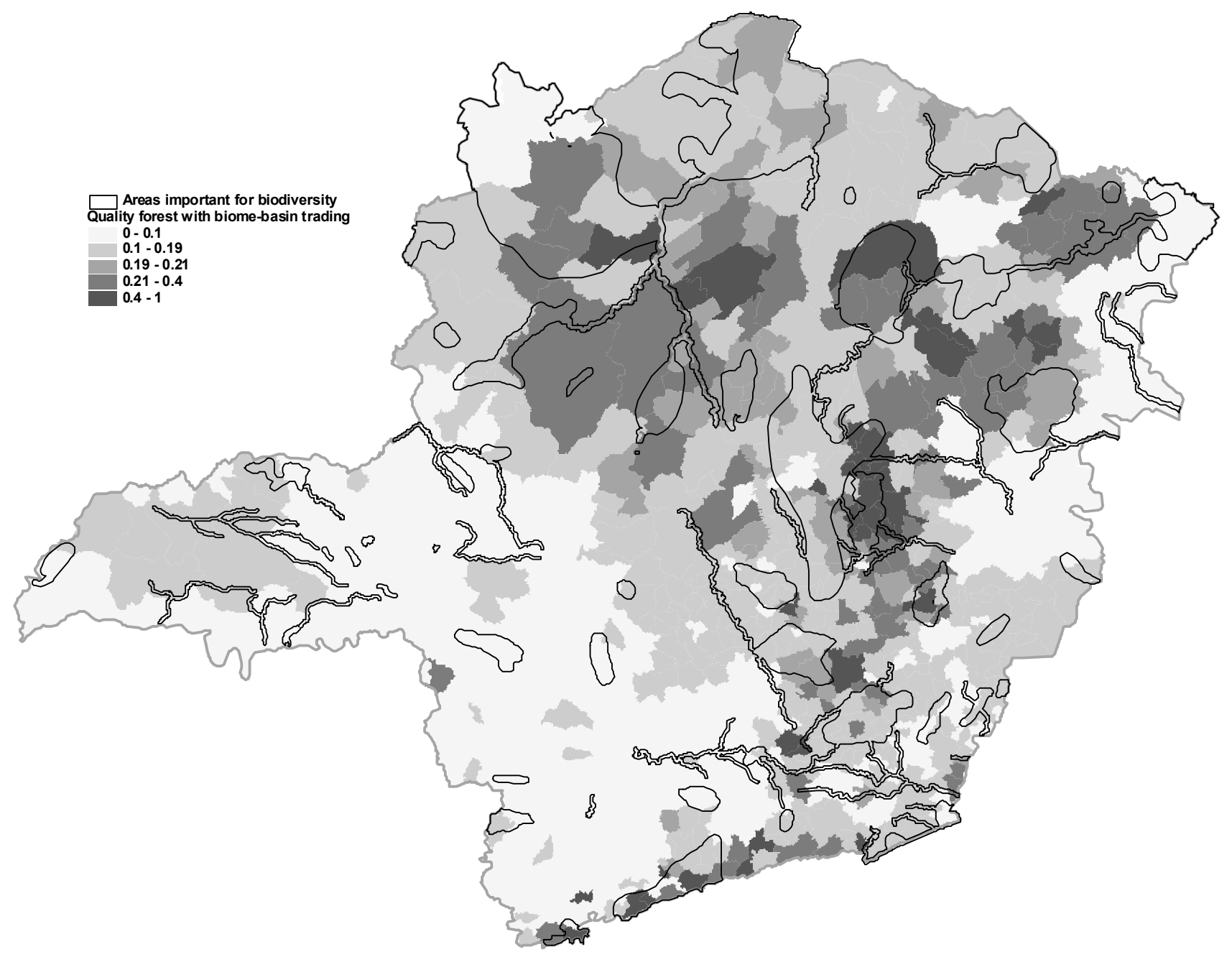


Chomitz, Thomas and Brandão Page 34

Figure 6 "Good-quality" forest cover with biome-wide trading

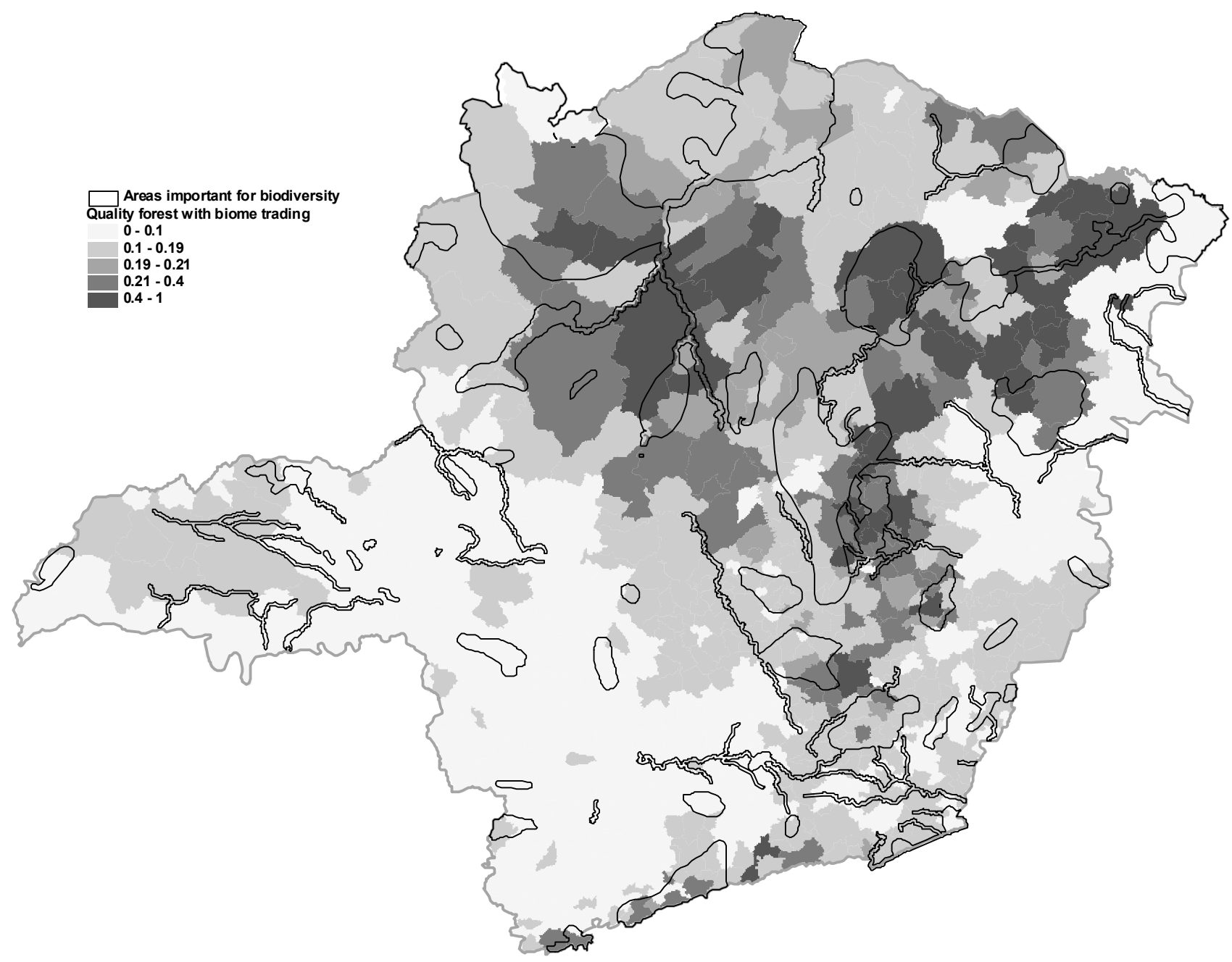

